\title{
Correction to: Perioperative antibiotic prophylaxis in long bone open fractures: the need for randomized controlled trials
}

\author{
Peter Declercq ${ }^{1,2} \cdot$ Charalampos Zalavras $^{3} \cdot$ Beatrijs Mertens $^{1} \cdot$ Lorenz Van der Linden $^{1,2} \cdot$ Stefaan Nijs $^{4,5}$. \\ Isabel Spriet ${ }^{1,2} \cdot$ Willem-Jan Metsemakers $^{4,5}$ (i)
}

Published online: 8 March 2021

(c) Springer-Verlag GmbH Germany, part of Springer Nature 2021

\section{Correction to: Archives of Orthopaedic and Trauma Surgery https://doi.org/10.1007/s00402-021-03796-1}

The original version of this article unfortunately contained a mistake. Given name and family name of authors were swapped.

The correct given and family names are:

Given name: Peter and Family name: Declercq Given name: Charalampos and Family name: Zalavras Given name: Beatrijs and Family name: Mertens Given name: Lorenz and Family Name: Van der Linden Given name: Stefaan and Family Name: Nijs Given name: Isabel and Family Name: Spriet Given name: Willem-Jan and Family Name: Metsemakers
The original article has been corrected

Publisher's Note Springer Nature remains neutral with regard to jurisdictional claims in published maps and institutional affiliations.

The original article can be found online at https://doi.org/10.1007/ s00402-021-03796-1.

Willem-Jan Metsemakers

willem-jan.metsemakers@uzleuven.be

1 Pharmacy Department, University Hospitals Leuven,

Leuven, Belgium

2 Department of Pharmaceutical and Pharmacological Sciences, Clinical Pharmacology and Pharmacotherapy, KU

Leuven, University of Leuven, Leuven, Belgium

3 Department of Orthopaedic Surgery, Keck School of Medicine, University of Southern California, Los Angeles, USA

4 Department of Trauma Surgery, University Hospitals Leuven, Leuven, Belgium

5 Department of Development and Regeneration, KU Leuven, University of Leuven, Leuven, Belgium 